Pressure Effect on the Structure and Super conduct i ng Transi t i on Temper at ure of Fi I l ed Skut ter udi tes LaT4P12 ( T=Fe, Ru)

\begin{tabular}{|l|l|}
\hline 著者 & $\begin{array}{l}\text { KAWAMRA Yuki hi ro, KAWAAI Takuna, HAYASH } \\
\text { Juni chi, SEK NE Chi hi ro, GOTO H r ot ada, } \\
\text { JI NGUANG Cheng, MATSUBAYASH Kazuyuki, } \\
\text { UMATOKO Yoshi ya }\end{array}$ \\
\hline $\begin{array}{l}\text { j our nal or } \\
\text { publ i cat i on t i t l e }\end{array}$ & Journal of the Physi cal Soci ety of Japan \\
\hline vol une & 82 \\
\hline page range & $114702-114702$ \\
\hline year & $2013-10-07$ \\
\hline URL & ht t p: //hdl . handl e. net /10258/2756 \\
\hline
\end{tabular}


Pressure Effect on the Structure and Super conduct i ng Transi t i on Temper at ure of Fi I l ed Skut ter udi tes LaT4P12 ( T=Fe, Ru)

\begin{tabular}{|l|l|}
\hline 著者 & $\begin{array}{l}\text { KAWAMRA Yuki hi ro, KAWAAI Takuna, HAYASH } \\
\text { Juni chi, SEK NE Chi hi ro, GOTO H r ot ada, } \\
\text { JI NGUANG Cheng, MATSUBAYASH Kazuyuki, } \\
\text { UMATOKO Yoshi ya }\end{array}$ \\
\hline $\begin{array}{l}\text { j our nal or } \\
\text { publ i cat i on t i t l e }\end{array}$ & Journal of the Physi cal Soci ety of Japan \\
\hline vol une & 82 \\
\hline page range & $114702-114702$ \\
\hline year & $2013-10-07$ \\
\hline URL & ht t p: //hdl . handl e. net /10258/2756 \\
\hline
\end{tabular}




\title{
Pressure Effect on the Structure and Superconducting Transition Temperature of Filled Skutterudites $\mathrm{LaT}_{\mathbf{4}} \mathrm{P}_{12}(T=\mathrm{Fe}, \mathrm{Ru})$
}

\author{
Yukihiro Kawamura $^{1}{ }^{*}$, Takuma KawaAi ${ }^{1}$, Junichi Hayashi ${ }^{1}$, Chihiro Sekine ${ }^{1}$, Hirotada \\ Gotou $^{2}$, Jinguang Cheng $^{2}$, Kazuyuki Matsubayashi ${ }^{2}$ and Yoshiya Uwatoko ${ }^{2}$ \\ ${ }^{1}$ Muroran Institute of Technology, Muroran, Hokkaido 050-8585, Japan \\ ${ }^{2}$ Institute for Solid State Physics, University of Tokyo, Kashiwa, Chiba 277-8581, Japan
}

We studied the effect of pressure on the superconducting transition temperature $T_{\mathrm{SC}}$ of $\mathrm{La}_{4} \mathrm{P}_{12}(T=\mathrm{Fe}, \mathrm{Ru})$ up to $8 \mathrm{GPa}$ through electrical resistivity measurements in a cubic anvil apparatus. The $T_{\mathrm{SC}}$ of $\mathrm{LaFe}_{4} \mathrm{P}_{12}$ was also determined through magnetization measurements up to $3.4 \mathrm{GPa}$ with an opposed-anvil pressure cell. In $\mathrm{LaFe}_{4} \mathrm{P}_{12}, T_{\mathrm{SC}}$ increases with pressure at a rate of $0.71 \mathrm{~K} / \mathrm{GPa}$ from $0 \mathrm{GPa}$ reaching its maximum at approximately $7 \mathrm{GPa}$. In contrast, the $T_{\mathrm{SC}}$ of $\mathrm{LaRu}_{4} \mathrm{P}_{12}$ monotonically decreases with pressure. The decrease rate gradually increases from -0.07 to $-0.29 \mathrm{~K} / \mathrm{GPa}$. The distinct pressure dependences of both $T_{\mathrm{SC}}$ 's cannot be explained solely from a structural point of view. We propose that the difference between the pressure dependence of $T_{\mathrm{SC}}$ for $\mathrm{LaFe}_{4} \mathrm{P}_{12}$ and that for $\mathrm{LaRu}_{4} \mathrm{P}_{12}$ can be attributed to the difference in the electronic density of states at the Fermi energy between these two compounds.

KEYWORDS: skutterudite, $\mathrm{LaFe}_{4} \mathrm{P}_{12}$, $\mathrm{LaRu}_{4} \mathrm{P}_{12}, \mathrm{LaT}_{4} \mathrm{P}_{12}$, superconductor, pressure, bulk modulus, density of states

\section{Introduction}

Ternary intermetallic compounds $\operatorname{Ln} T_{4} X_{12}$ ( $\mathrm{Ln}=$ Lanthanide, $T=$ transition metal, $X=$ pnictogens) crystallize in the filled-skutterudite structure (space group $\operatorname{Im} \overline{3}$, No. 204). ${ }^{1}$ Depending on the combination of elements, filled skutterudite compounds show various features. Filled skutterudite antimonids have attracted much attention owing to their improved thermoelectric properties. ${ }^{2,3)}$ Filled skutterudite phosphides exhibit interesting physical phenomena: praseodymium-based materials exhibit metal-insulator (MI) transition, ${ }^{4,5)}$ multipole ordering, ${ }^{6)}$ and heavy-fermion behavior under magnetic fields, ${ }^{7,8)}$ cerium compounds show Kondo semiconducting behavior; ${ }^{9,10)}$ lanthanum compounds exhibit superconductivity. ${ }^{11)}$ These interesting physical properties are believed to arise from the Fermi surface insta-

\footnotetext{
*E-mail: y_kawamura@mmm.muroran-it.ac.jp
} 
bility. ${ }^{12)}$ Nesting properties are observed in the Fermi surface of $\mathrm{LaFe}_{4} \mathrm{P}_{12}{ }^{13)}$ and $\mathrm{LaRu}_{4} \mathrm{P}_{12} .{ }^{14)}$ Such nesting properties may be the origin of the MI transition in $\operatorname{PrRu}_{4} \mathrm{P}_{12} .{ }^{15,16)}$ Among the various physical properties connected to this unique Fermi surface, in the present work, superconductivity is focused on. Thus far, 19 filled skutterudite compounds have been found to be superconductors. Among them, $\mathrm{La}_{4} \mathrm{P}_{12}(T=\mathrm{Fe}, \mathrm{Ru}, \mathrm{Os})$ have a distinct characteristic in terms of the pressure dependence of the superconducting transition temperature $\left(T_{\mathrm{SC}}\right)$. The $T_{\mathrm{SC}}$ 's of $\mathrm{LaFe}_{4} \mathrm{P}_{12}, \mathrm{LaRu}_{4} \mathrm{P}_{12}$, and $\mathrm{LaOs}_{4} \mathrm{P}_{12}$ at ambient pressures are 4.1, 7.2, and $1.8 \mathrm{~K}$, respectively. ${ }^{11,17)}$ In a previous high-pressure study up to $1.8 \mathrm{GPa},{ }^{17)}$ the $T_{\mathrm{SC}}$ of $\mathrm{LaFe}_{4} \mathrm{P}_{12}$ was found to increase at a rate of $0.72 \mathrm{~K} / \mathrm{GPa}$, while those of $\mathrm{LaRu}_{4} \mathrm{P}_{12}$ and $\mathrm{LaOs}_{4} \mathrm{P}_{12}$ decrease gradually at rates of -0.16 and $-0.095 \mathrm{~K} / \mathrm{GPa}$, respectively. DeLong and Meisner ${ }^{17)}$ suggested that the pressure dependence of $T_{\mathrm{SC}}$ can be explained by two competing contributions: the suppression of $T_{\mathrm{SC}}$ due to the compression of the lattice (i.e., a decrease in volume), and the enhancement of $T_{\mathrm{SC}}$ due to the effect of pressure on La itself. However, a mechanism relying only on the structure of the filled skutterudite is not completely consistent with all physical properties. One reason is that the Fermi surface properties of $L a T_{4} \mathrm{P}_{12}$, which lead to many intriguing physical properties, were not taken into account. $T_{\mathrm{SC}}$ is also related to the density of states (DOS) at the Fermi surface. In order to verify the mechanism proposed by DeLong and Meisner ${ }^{17)}$ and to clarify the origin of the distinct pressure dependence of $T_{\mathrm{SC}}$, we investigated the pressure dependence of $T_{\mathrm{SC}}$ in $\mathrm{La}_{4} \mathrm{P}_{12}$ in an extended pressure range up to 8 GPa.

\section{Experimental Procedure}

Polycrystalline $\mathrm{La}_{4} \mathrm{P}_{12}(T=\mathrm{Fe}, \mathrm{Ru})$ was prepared at high temperature and high pressure using a wedge-type cubic anvil apparatus. Stoichiometric amounts of each metal and red phosphorus powder were reacted at $1050{ }^{\circ} \mathrm{C}$ under a pressure of $4.5 \mathrm{GPa}$ for $0.5 \mathrm{~h}$. The resulting sample was a cylinder of $2.5 \mathrm{~mm}$ diameter and $6 \mathrm{~mm}$ length. Single crystals of $\mathrm{La} T_{4} \mathrm{P}_{12}$ were also grown by a Sn flux method. The starting materials were $\mathrm{La}, \mathrm{Fe}$ (or $\mathrm{Ru}$ ), red $\mathrm{P}$, and $\mathrm{Sn}$ mixed in an atomic ratio of 1:4:20:50, sealed in vacuum, heated to $1050{ }^{\circ} \mathrm{C}$, and then cooled to $680{ }^{\circ} \mathrm{C}$ at a rate of $1{ }^{\circ} \mathrm{C} / \mathrm{h}$. Sn flux was removed by centrifugation, followed by etching in an aqueous solution of $6 \mathrm{~mol} / \mathrm{L} \mathrm{HCl}$. The size of the resulting $\mathrm{LaFe}_{4} \mathrm{P}_{12}$ single crystals was up to $1.5 \mathrm{~mm}$, while that of $\mathrm{LaRu}_{4} \mathrm{P}_{12}$ was less than $100 \mu \mathrm{m}$. The phase purity of the resulting compounds was identified by powder X-ray diffraction analysis. The impurity level was less than $1 \%$ for all the samples. In order to determine the bulk modulus of $\mathrm{LaRu}_{4} \mathrm{P}_{12}$, we also performed high-pressure powder X-ray diffraction measurements using synchrotron 


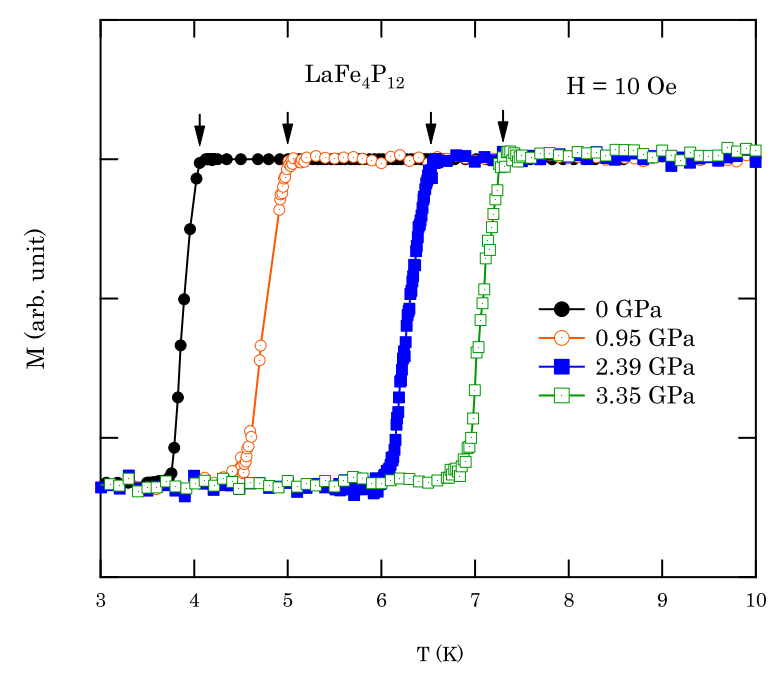

Fig. 1. (Color online) Temperature dependences of magnetization of $\mathrm{LaFe}_{4} \mathrm{P}_{12}$ measured at $\mathrm{H}=10 \mathrm{Oe}$ after zero-field cooling under various pressures. The arrows indicate the onset of the superconductivity.

radiation with a wavelength $\lambda=0.62 \AA$ at BL-18C of the Photon Factory in Tsukuba, Japan. An imaging plate was used as the detector. The pressure was applied by a diamond anvil cell filled with a 4:1 mixture of methanol/ethanol as the pressure-transmitting medium. The applied pressure was determined by a ruby fluorescence method. Single-crystal $\mathrm{LaFe}_{4} \mathrm{P}_{12}$ and polycrystalline $\mathrm{LaRu}_{4} \mathrm{P}_{12}$ were used for resistivity and magnetization measurements. Magnetization under pressure was measured with a Magnetic Properties Measurement System (MPMS, Quantum Design Inc.). Pressure was applied using an opposed-anvil type ceramic pressure cell, ${ }^{18)}$ where pressure was monitored by tracking the $T_{\mathrm{SC}}$ of Sn. Electrical resistivity under pressure was measured with a cubic-anvil apparatus. Glycerin was used as the pressure medium in order to achieve hydrostatic conditions.

\section{Results}

Figure 1 shows the temperature dependences of the magnetization of $\mathrm{LaFe}_{4} \mathrm{P}_{12}$ measured at $\mathrm{H}=10$ Oe after zero-field cooling at various pressures. A distinct drop upon cooling due to the Meissner effect of superconductivity is observed at $4.1 \mathrm{~K}$ at ambient pressure. $T_{\mathrm{SC}}$ is defined by the onset of superconductivity, as indicated by the arrows. $T_{\mathrm{SC}}$ increases monotonically with increasing pressure.

Figure 2 shows the temperature dependence of the resistivity of $\mathrm{LaFe}_{4} \mathrm{P}_{12}$ up to $8 \mathrm{GPa}$. A drop in resistivity caused by superconductivity is observed at $4.9 \mathrm{~K}$, followed by a zero resistivity at $4.5 \mathrm{~K}$ under $0 \mathrm{GPa}$. The sharpness of the drop in $\rho(T)$ is sensitive to the measurement conditions. The difference between the onset and offset of superconductivity is $\sim 0.5 \mathrm{~K}$ at 0 


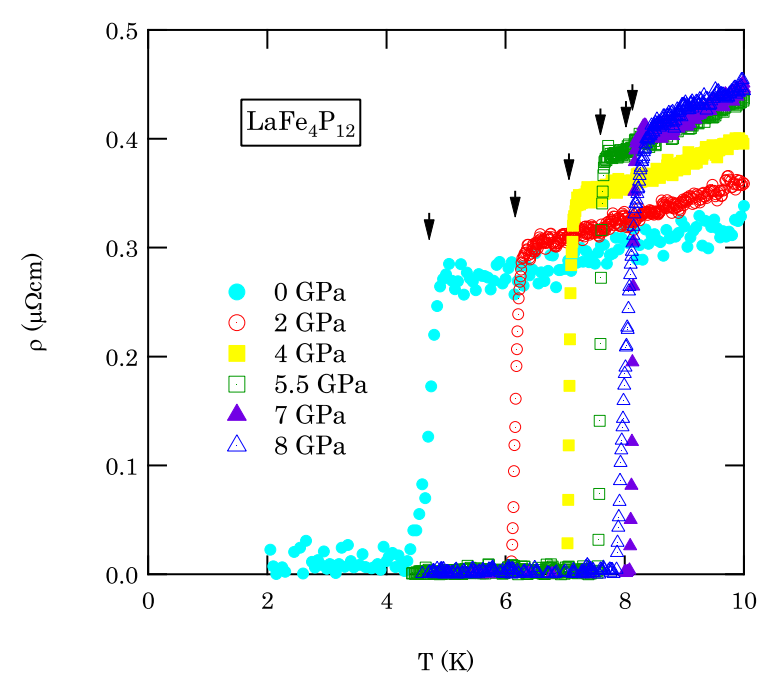

Fig. 2. (Color online) Temperature dependences of electrical resistivity on $\mathrm{LaFe}_{4} \mathrm{P}_{12}$ at various pressures. The arrows indicate the midpoint of superconductivity.

$\mathrm{GPa}$; it is $\sim 0.2 \mathrm{~K}$ from 2 to $7 \mathrm{GPa}$. Since the sample measured at $0 \mathrm{GPa}$ is the same as that measured under pressure, the difference can probably be attributed to the measuring apparatus. The resistivity drop broadens slightly at $8 \mathrm{GPa}$. The difference between the onset and offset of superconductivity is $\sim 0.5 \mathrm{~K}$ and may be attributed to the change in the hydrostatic conditions. Although the pressure medium, i.e. glycerin, produces good hydrostatic conditions even above $5 \mathrm{GPa},{ }^{19)}$ the hydrostatic pressure conditions may deteriorate gradually at over $6 \mathrm{GPa}$, at which point glycerin solidifies. We define $T_{\mathrm{SC}}$ as the temperature midway between the onset and offset of superconductivity.

Figure 3 shows the temperature dependence of resistivity for $\mathrm{LaRu}_{4} \mathrm{P}_{12}$ up to $8 \mathrm{GPa}$. A drop in resistivity caused by superconductivity is observed, followed by a zero resistivity. We define $T_{\mathrm{SC}}$ in the same way as mentioned previously for resistivity measurements. $T_{\mathrm{SC}}$ decreases with increasing pressure. We note that the $\rho$ for $\mathrm{LaRu}_{4} \mathrm{P}_{12}$ in the normal conducting state is nearly a thousand times higher than that for $\mathrm{LaFe}_{4} \mathrm{P}_{12}$. This increase can be attributed to the difference in sample quality because $\mathrm{LaFe}_{4} \mathrm{P}_{12}$ was measured in single-crystal form, while $\mathrm{LaRu}_{4} \mathrm{P}_{12}$ was measured in polycrystalline form. The residual resistivity ratio (RRR) of $\mathrm{LaFe}_{4} \mathrm{P}_{12}$ is 560 , while that of $\mathrm{LaRu}_{4} \mathrm{P}_{12}$ is 7 .

Figure 4 shows the pressure dependence of $T_{\mathrm{SC}}$. The $T_{\mathrm{SC}}$ of $\mathrm{LaRu}_{4} \mathrm{P}_{12}$ decreases monotonically with increasing pressure. The pressure coefficient $\mathrm{d} T_{\mathrm{SC}} / \mathrm{d} P$ slightly increases from $-0.07(5) \mathrm{K} / \mathrm{GPa}$ in the range of 0 to $2 \mathrm{GPa}$ to $-0.29(0) \mathrm{K} / \mathrm{GPa}$ from 6 to $8 \mathrm{GPa}$. Although the $\mathrm{d} T_{\mathrm{SC}} / \mathrm{d} P$ obtained in this study is slightly different from that of $-0.16 \mathrm{~K} / \mathrm{GPa}$ at $1.8 \mathrm{GPa}$ found 


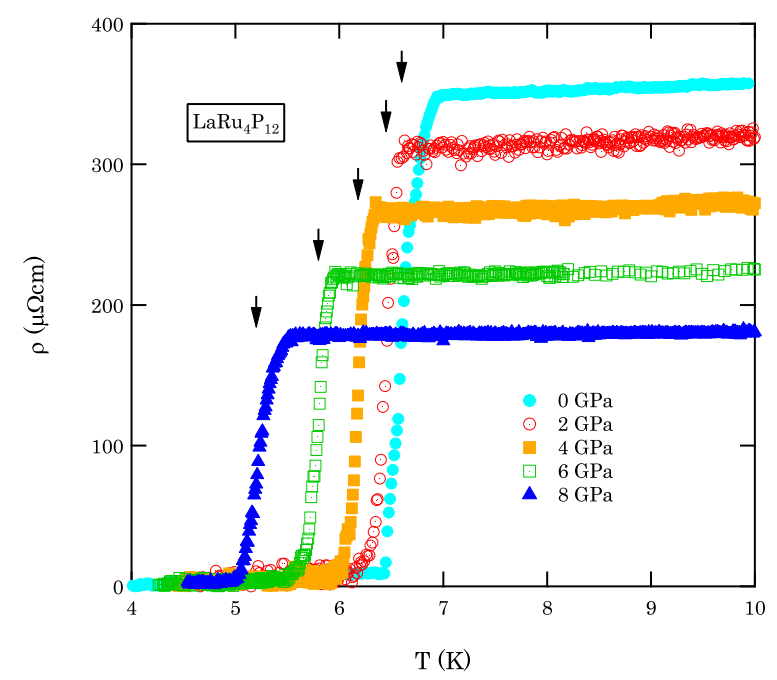

Fig. 3. (Color online) Temperature dependences of resistivity for $\mathrm{LaRu}_{4} \mathrm{P}_{12}$ up to $8 \mathrm{GPa}$. The arrows indicate the midpoint of superconductivity.

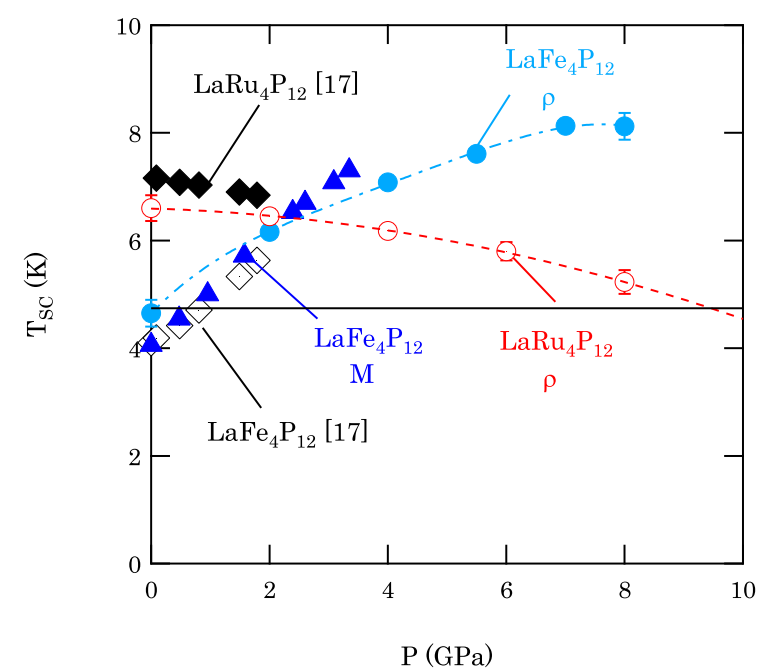

Fig. 4. (Color online) Pressure dependence of $T_{\mathrm{SC}}$ for $\mathrm{LaFe}_{4} \mathrm{P}_{12}$ investigated by magnetization (closed triangle) and resistivity (closed circle) measurements. Corresponding measurements for $\mathrm{LaRu}_{4} \mathrm{P}_{12}$ (open circle) are also shown. The dashed-dotted line and dashed line are guide lines of the pressure dependences of the $T_{\mathrm{SC}}$ 's of $\mathrm{LaFe}_{4} \mathrm{P}_{12}$ and $\mathrm{LaRu}_{4} \mathrm{P}_{12}$, respectively. Previously reported values for $\mathrm{LaFe}_{4} \mathrm{P}_{12}$ (open diamond) and $\mathrm{LaRu}_{4} \mathrm{P}_{12}$ (closed diamond) are also plotted. ${ }^{17)}$ The solid line indicates the $T_{S C}$ of $\mathrm{LaFe}_{4} \mathrm{P}_{12}$ at ambient pressure.

in a previous study, ${ }^{17)}$ the gradual decrease in $T_{\mathrm{SC}}$ with pressure found here is consistent with the results of previous studies. In contrast, the $T_{\mathrm{SC}}$ of $\mathrm{LaFe}_{4} \mathrm{P}_{12}$ increases rapidly with increasing pressure. Below $2 \mathrm{GPa}$, the $\mathrm{d} T_{\mathrm{SC}} / \mathrm{dP}$ for $\mathrm{LaFe}_{4} \mathrm{P}_{12}$ as determined from magnetization measurements is $1.04 \mathrm{~K} / \mathrm{GPa}$ and that from electrical resistivity is $0.71 \mathrm{~K} / \mathrm{GPa}$. This rapid increase is consistent with the value of $0.72 \mathrm{~K} / \mathrm{GPa}$ in a previous report. ${ }^{17)}$ The slight dif- 


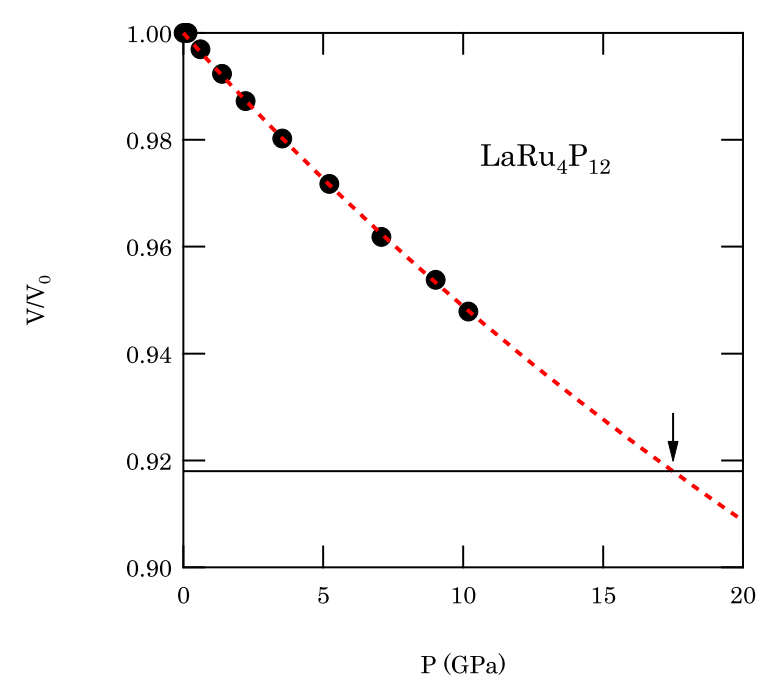

Fig. 5. (Color online) Pressure dependence of volume on $\mathrm{LaRu}_{4} \mathrm{P}_{12}$ normalized at ambient pressure. The dotted line indicates the fit to the Birch-Murnaghan equation of state. See text for details. The solid line corresponds to the volume of $\mathrm{LaFe}_{4} \mathrm{P}_{12}$ at ambient pressure.

ference in $\mathrm{d} T_{\mathrm{SC}} / \mathrm{dP}$ can probably be attributed to the difference in hydrostatic pressure conditions. The cubic anvil pressure cell for electrical resistivity measurements can achieve a better hydrostatic pressure condition than the opposed-anvil type cell used for magnetization measurements. The $\mathrm{d} T_{\mathrm{SC}} / \mathrm{dP}$ determined from magnetization measurements is well reproducible with a difference of less than $2 \%$ in two separated runs. Above $2 \mathrm{GPa}, \mathrm{d} T_{\mathrm{SC}} / \mathrm{d} P$ gradually decreases with pressure, and $T_{\mathrm{SC}}$ seems to reach its maximum of approximately $7 \mathrm{GPa}$.

\section{Discussion}

Before discussing the pressure dependence of $T_{\mathrm{SC}}$, we explain the relation between $\mathrm{LaFe}_{4} \mathrm{P}_{12}$ and $\mathrm{LaRu}_{4} \mathrm{P}_{12}$. Fe and $\mathrm{Ru}$ are in the same group in the periodic table and the radius of the $\mathrm{Fe}$ ion is smaller than that of the $\mathrm{Ru}$ ion. Thus, substituting $\mathrm{Fe}$ for $\mathrm{Ru}$ in $\mathrm{LaRu}_{4} \mathrm{P}_{12}$ causes a decrease in volume due to chemical pressure. To clarify the relation between $\mathrm{LaFe}_{4} \mathrm{P}_{12}$ and $\mathrm{LaRu}_{4} \mathrm{P}_{12}$ from a structural point of view, we applied physical pressure on $\mathrm{LaRu}_{4} \mathrm{P}_{12}$. Figure 5 shows the pressure dependence of the unit-cell volume of $\mathrm{LaRu}_{4} \mathrm{P}_{12}$, obtained from a synchrotron X-ray study at a pressure of up to $10 \mathrm{GPa}$. The dotted line indicates a fit to the Birch-Murnaghan equation of state:20)

$$
P=\frac{3}{2} B_{0}\left\{\left(\frac{V}{V_{0}}\right)^{-\frac{7}{3}}-\left(\frac{V}{V_{0}}\right)^{-\frac{5}{3}}\right\}\left[1+\frac{3}{4}\left(B_{0}^{\prime}-4\right)\left\{\left(\frac{V}{V_{0}}\right)^{-\frac{2}{3}}-1\right\}\right],
$$

where $\mathrm{P}$ is the pressure, $\mathrm{V}$ is the volume, $\mathrm{V}_{0}$ is the volume at $0 \mathrm{GPa}, \mathrm{B}_{0}$ is the bulk modulus, and $\mathrm{B}_{0}$ ' is the first derivative of $\mathrm{B}_{0}$. The fitted line is obtained from the data below $10 \mathrm{GPa}$. 
Table I. Lattice parameters and bulk moduli of $\mathrm{La}_{4} \mathrm{P}_{12}(T=\mathrm{Fe}, \mathrm{Ru})$.

\begin{tabular}{lll}
\hline & $\mathrm{LaFe}_{4} \mathrm{P}_{12}$ & $\mathrm{LaRu}_{4} \mathrm{P}_{12}$ \\
\hline $\mathrm{a}(\AA)$ & 7.8311 & 8.05645 \\
$\mathrm{~V}\left(\AA^{3}\right)$ & 480.251 & 522.9151 \\
$\mathrm{~B}_{0}(\mathrm{GPa})$ & $150^{23)}$ & 170 \\
\hline
\end{tabular}

We obtained a $\mathrm{B}_{0}$ of $170 \mathrm{GPa}$ for our sample, which is consistent with the value of $172 \mathrm{GPa}$ observed in a previous study. ${ }^{21,22)}$ Table I shows the lattice constants and unit-cell volumes at ambient pressure in addition to the bulk moduli of $\mathrm{La}_{4} \mathrm{P}_{12}(T=\mathrm{Fe}, \mathrm{Ru})$. From Table I, the unit-cell volume of $\mathrm{LaFe}_{4} \mathrm{P}_{12}$ is $91.8 \%$ of that of $\mathrm{LaRu}_{4} \mathrm{P}_{12}$. In Fig. 5, the solid line indicates 91.8\% of the unit-cell volume of $\mathrm{LaRu}_{4} \mathrm{P}_{12}$ at ambient pressure, corresponding to the volume of $\mathrm{LaFe}_{4} \mathrm{P}_{12}$. Extrapolating the fit to the Birch-Murnaghan equation of state indicates that $\mathrm{V} / \mathrm{V}_{0}$ will reach 0.918 at $17.5 \mathrm{GPa}$, as indicated by the arrow in Fig. 5. Thus, the structure of $\mathrm{LaFe}_{4} \mathrm{P}_{12}$ at ambient pressure corresponds to that of $\mathrm{LaRu}_{4} \mathrm{P}_{12}$ at $17.5 \mathrm{GPa}$.

We discuss the difference in the pressure dependence of $T_{\mathrm{SC}}$ between $\mathrm{LaFe}_{4} \mathrm{P}_{12}$ and $\mathrm{LaRu}_{4} \mathrm{P}_{12}$. DeLong and Meisner proposed that the pressure dependence of $T_{\mathrm{SC}}$ can be attributed to the crystal structure. ${ }^{17)}$ Their arguments are reproduced here. When the $12 \mathrm{P}$ cage structure around $\mathrm{La}$ is too small for $\mathrm{La}$ atoms as in $\mathrm{LaFe}_{4} \mathrm{P}_{12}$, pressure acts directly on the $\mathrm{La}$ site. In this situation, $T_{\mathrm{SC}}$ increases with pressure because the $T_{\mathrm{SC}}$ of La increases with pressure. When the cage structure is too large for $\mathrm{LaRu}_{4} \mathrm{P}_{12}$, pressure does not affect La atoms. In this situation, $T_{\mathrm{SC}}$ decreases with pressure owing to the contraction of the skutterudite structure. However, this idea is questionable for the following two reasons. (1) If the pressure dependence of $T_{\mathrm{SC}}$ is attributed solely to the crystal structure, the contraction of $\mathrm{LaRu}_{4} \mathrm{P}_{12}$ with pressure should lead to similar properties to $\mathrm{LaFe}_{4} \mathrm{P}_{12}$. In Fig. 4, the dashed line is the guide line of the pressure dependence of $T_{\mathrm{SC}}$ of $\mathrm{LaRu}_{4} \mathrm{P}_{12}$ below $8 \mathrm{GPa}$. If this guide line is extrapolated to $10 \mathrm{GPa}$, it reaches $4.7 \mathrm{~K}$ at $9.5 \mathrm{GPa}$. $\mathrm{LaFe}_{4} \mathrm{P}_{12}$ has a $T_{\mathrm{SC}}$ of $4.7 \mathrm{~K}$ at ambient pressure. Thus, $\mathrm{LaRu}_{4} \mathrm{P}_{12}$ has the same unit-cell volume as $\mathrm{LaFe}_{4} \mathrm{P}_{12}$ at $17.5 \mathrm{GPa}$, but has the same $T_{\mathrm{SC}}$ as $\mathrm{LaFe}_{4} \mathrm{P}_{12}$ at $9.5 \mathrm{GPa}$. The difference between these pressures suggests that $T_{\mathrm{SC}}$ should not be attributed solely to the structure. (2) The $T_{\mathrm{SC}}$ of La increases up to $20 \mathrm{GPa} .{ }^{24)}$ If this increase in $T_{\mathrm{SC}}$ can be attributed to the superconductivity associated with the La atom only, the $T_{\mathrm{SC}}$ of $\mathrm{LaFe}_{4} \mathrm{P}_{12}$ should also increase with pressure up to at least $20 \mathrm{GPa}$. In contrast, our results in Fig. 4 reveal that the $T_{\mathrm{SC}}$ of $\mathrm{LaFe}_{4} \mathrm{P}_{12}$ actually reaches its maximum at approximately $7 \mathrm{GPa}$. 
Here, we suggest that the origin of the pressure dependence of $T_{\mathrm{SC}}$ is associated with the DOS at the FL. ${ }^{139} \mathrm{La},{ }^{31} \mathrm{P}-\mathrm{NMR}$ studies revealed that $\mathrm{LaFe}_{4} \mathrm{P}_{12}$ can be classified as a spin-singlet s-wave superconductor with a weak-electron-phonon-coupling parameter of $\lambda=$ $0.2^{25,26)}$ and a superconducting gap of $2 \Delta /\left(k_{\mathrm{B}} \mathrm{T}_{\mathrm{SC}}\right)=3.8 .{ }^{26)}$ In weakly coupled superconductors, $T_{\mathrm{SC}}$ is related to the density of the state at the Fermi energy $N\left(E_{\mathrm{F}}\right)$ through the relation

$$
T_{\mathrm{SC}} \sim 1.14 \theta_{\mathrm{D}} \exp \left[\frac{-1}{N\left(E_{\mathrm{F}}\right) V}\right],
$$

where $\theta_{\mathrm{D}}$ is the Debye temperature and $\mathrm{V}$ is the potential energy of phonon-electron interaction. $T_{\mathrm{SC}}$ is more sensitive to $N\left(E_{\mathrm{F}}\right) \mathrm{V}$ than to $\theta_{\mathrm{D}}$. The $N\left(E_{\mathrm{F}}\right) \mathrm{Vs}$ of $\mathrm{LaFe}_{4} \mathrm{P}_{12}$ and $\mathrm{LaRu}_{4} \mathrm{P}_{12}$ seem similar because these compounds are isostructural and $\mathrm{Fe}$ and $\mathrm{Ru}$ are of the same family, as mentioned above. However, their $N\left(E_{\mathrm{F}}\right) \mathrm{s}$ may exhibit a distinct response to pressure. Although the calculated energy band structure for $\mathrm{LaRu}_{4} \mathrm{P}_{12}$ shows that the FL is situated in a large peak at the DOS, ${ }^{27)}$ a sub-millielectronvolt resolution photoemission spectroscopy (PES) study could not detect such a structure. ${ }^{28)}$ From the PES study, the DOS decreases with increasing energy around the FL. On the other hand, the FL of $\mathrm{LaFe}_{4} \mathrm{P}_{12}$ is slightly below the local maximum calculated total density of states for the 48th band. ${ }^{13)}$ These findings can explain why the $\mathrm{d} T_{\mathrm{SC}} / \mathrm{dP}$ of $\mathrm{LaFe}_{4} \mathrm{P}_{12}$ is much higher than that of $\mathrm{LaRu}_{4} \mathrm{P}_{12}$. If the local maximum of the DOS and the Fermi level approach each other with pressure application, $N\left(E_{\mathrm{F}}\right)$ and $T_{\mathrm{SC}}$ should rapidly increase. From our results, the $T_{\mathrm{SC}}$ of $\mathrm{LaFe}_{4} \mathrm{P}_{12}$ peaks above $7 \mathrm{GPa}$. This suggests that the Fermi level is located at the local maximum of the DOS at approximately $7 \mathrm{GPa}$. In order to verify our assumption, theoretical or experimental study of the Fermi surface under pressure is needed.

\section{Conclusions}

We have studied the pressure dependence of the $T_{\mathrm{SC}}$ of $\mathrm{La}_{4} \mathrm{P}_{12}(T=\mathrm{Fe}, \mathrm{Ru})$ up to $8 \mathrm{GPa}$. Our present study extends the scope of previous works by measuring the pressure dependence of $T_{\mathrm{SC}}$ up to $8 \mathrm{GPa}$. The pressure dependence of $T_{\mathrm{SC}}$ for $\mathrm{LaFe}_{4} \mathrm{P}_{12}$ is confirmed by resistivity and magnetization measurements. The $T_{\mathrm{SC}}$ of $\mathrm{LaRu}_{4} \mathrm{P}_{12}$ decreases monotonically at rates of $0.07-0.29 \mathrm{~K} / \mathrm{GPa}$. In contrast, the $T_{\mathrm{SC}}$ of $\mathrm{LaFe}_{4} \mathrm{P}_{12}$ increases at rates of $0.71-1.04 \mathrm{~K} / \mathrm{GPa}$ below $2 \mathrm{GPa}$. The rate of increase of $T_{\mathrm{SC}}$ with pressure for $\mathrm{LaFe}_{4} \mathrm{P}_{12}$ gradually decreases and $T_{\mathrm{SC}}$ seems to reach its maximum at approximately $7 \mathrm{GPa}$. We suggest that the difference in the pressure dependence of $T_{\mathrm{SC}}$ between $\mathrm{LaRu}_{4} \mathrm{P}_{12}$ and $\mathrm{LaFe}_{4} \mathrm{P}_{12}$ can be attributed to the difference in the response of the electronic DOS at the Fermi level to pressure. 


\section{Acknowledgments}

This work was supported by a Grant-in-Aid for Scientific Research on Innovative Areas

“ Heavy Electrons" (No. 20102004) from the Ministry of Education, Culture, Sports, Science and Technology, Japan, and by a Grant-in-Aid for Scientific Research B (No. 23340092) from the Japan Society for the Promotion of Science. We acknowledge the support from Muroran Institute of Technology [a grant for the Kidorui (Rare Earth) Program]. JGC acknowledges the financial support in the form of a JSPS fellowship for foreign researchers (Grant No. 12F02023). 


\section{References}

1) W. Jeitschko and D. J. Braun: Acta Crystallogr., Sect. B 33 (1977) 3401.

2) B. C. Sales, D. Mandrus, and R. K. Williams: Science 272 (1996) 1325.

3) V. Keppens, D. Mandrus, B. C. Sales, B. C. Chakoumakos, P. Dai, R. Coldea, M. B. Maple, D. A. Gajewski, E. J. Freeman, and S. Bennington: Nature 395 (1998) 876.

4) C. Sekine, T. Uchiumi, I. Shirotani, and T. Yagi: Phys. Rev. Lett. 79 (1997) 3218.

5) S. H. Curnoe, K. Ueda, H. Harima, and K. Takegahara: J. Phys. Chem. Solids 63 (2002) 1207.

6) L. Hao, K. Iwasa, M. Nakajima, D. Kawana, K. Kuwahara, M. Kohgi, H. Sugawara, T. D. Matsuda, Y. Aoki, and H. Sato: Acta Phys. Pol. B 34 (2003) 1113.

7) H. Sato, Y. Abe, H. Okada, T.D. Matsuda, K. Abe, H. Sugawara, and Y. Aoki: Phys. Rev. B 62 (2000) 15125.

8) H. Sugawara, T. D. Matsuda, K. Abe, Y. Aoki, H. Sato, S. Nojiri, Y. Inada, R. Settai, and Y. Ōnuki: J. Magn. Magn. Mater. 226-230 (2001) 48.

9) F. Grandjean, A. Gerard, D. J. Braung, and W. Jeitschko: J. Phys. Chem. Solids 45 (1984) 877.

10) I. Shirotani, T. Uchiumi, C. Sekine, M. Hori, S. Kimura, and N. Hamaya: J. Solid State Chem. 142 (1999) 146.

11) G. P. Meisner: Physica B 108 (1981) 763.

12) H. Harima and K. Takegahara: J. Phys.: Condens. Matter 15 (2003) S2081.

13) H. Sugawara, Y. Abe, Y. Aoki, H. Sato, M. Hedo, R. Settai, Y. Onuki, and H. Harima: J. Phys. Soc. Jpn. 69 (2000) 2938.

14) S. R. Saha, H. Sugawara, R. Sakai, Y. Aoki, H. Sato, Y. Inada, H. Shishido, R. Settai, Y. Ōnuki, and H. Harima: Physica B 328 (2002) 68.

15) H. Harima and K. Takegahara: Physica B 312/313 (2002) 843.

16) H. Harima, K. Takegahara, K. Ueda, and S. H. Curnoe: Acta Phys. Pol. B 34 (2002) 1189.

17) L. E. DeLong and G. P. Meisner: Solid State Commun. 53 (1985) 119.

18) N. Tateiwa, Y. Haga, Z. Fisk, and Y. Ōnuki: Rev. Sci. Instrum. 82 (2011) 053906.

19) N. Mohri, K. Murata, Y. Uwatoko, and H. Takahashi: Kouatsu Gijutsu Handbook (Maruzen, Tokyo, 2007) p. 54 [in Japanese]. 
20) F. Birch: Phys. Rev. 71 (1947) 809.

21) I. Shirotani, T. Noro, J. Hayashi, C. Sekine, R. Giri, and T. Kikegawa: J. Phys.: Condens. Matter: 16 (2004) 7853.

22) J. Hayashi, I. Shirotani, K. Takeda, T. Uchiumi, S. Kimura, T. Adachi, and T. Kikegawa: in Science and Technology of High Pressure, Proceedings of AIRAPT - 17, ed. M. H. Manghnani, W. J. Nellis, and M. F. Nicol (Universities Press, Hyderabad, 2000) Vol. 2, p. 722 .

23) J. Hayashi, K. Akahira, K. Matsui, H. Ando, Y. Sugiuchi, K. Takeda, C. Sekine, I. Shirotani, and T. Yagi: J. Phys.: Conf. Ser. 215 (2010) 012142.

24) H. Balster and J. Wittig: J. Low Temp. Phys. 21 (1975) 377.

25) G. K. Shenoy, D. R. Noakes, and G. P. Meisner: J. Appl. Phys. 53 (1982) 2628.

26) Y. Nakai, K. Ishida, D. Kikuchi, H. Sugawara, and H. Sato: J. Phys. Soc. Jpn. 74 (2005) 3370.

27) H. Harima: Prog. Theor. Phys. Suppl. 138 (2000) 117.

28) S. Tsuda, T. Yokoya, T. Kiss, T. Shimojima, S. Shin, T. Togasi, S. Watanabe, C. Q. Zhang, C. T. Chen, H. Sugawara, H. Sato, and H. Harima: J. Phys. Soc. Jpn. 75 (2006) 064711. 